\title{
COM OS PÉS UM POUCO FORA DO CHÃO: TEXTO-PREPARADO E CITAÇÃO NOS ESCRITOS DE JOHN CAGE
}

Miguel de Ávila DUARTE*

RESUMO

O presente trabalho se propõe a investigar o uso dos procedimentos de citação na obra escrita do compositor estadunidense John Cage, em diálogo com as formulações teóricas do trabalho da citação de Antoine Compagnon. Caracterizada muitas vezes como uma "escrita através", a produção textual cageana será investigada por meio da noção de texto-preparado, derivada da ideia de retórica preparada, desenvolvida por David Patterson por analogia às preparações que o compositor realizava para execução de algumas obras suas para piano.

Palavras-Chave: Citação. Escrita experimental. John Cage.

À primeira vista, o ato de citar pode parecer uma decorrência como que "natural" da escrita. É certamente muito anterior ao momento em que a produção industrial de papel e, na sequência, de material impresso descartável possibilitaram a brincadeira infantil de recortar tais materiais, imagem que Compagnon (1996) elege para discutir o trabalho da citação. Mais ainda, a citação é igualmente anterior ao exaustivo trabalho artesanal dos monges copistas do medievo, que cuidadosamente reaproveitavam o precioso pergaminho na produção dos seus palimpsestos. Pensando para além do âmbito da escrita, o ato de relatar palavras de terceiros ausentes é mesmo um dos milagres da linguagem, elemento fundamental para a existência de todas as culturas humanas. Por outro lado, o ato de retomar palavras de terceiros - registradas hoje não apenas em texto, mas

Doutor em Teoria da Literatura e Literatura Comparada pela Universidade Federal de Minas Gerais/UFMG, Belo Horizonte, Minas Gerais, Brasil.

E-mail: maviladuarte@gmail.com Orcid iD: https://orcid.org/0000-0001-6366-2464 
igualmente enquanto sons e imagens - é continuamente modificado tanto por circunstâncias históricas e tecnológicas como por escolhas, invenções e limitações de natureza estética, cultural, social e política. $\mathrm{O}$ ato imemorial de citar é também a base da literatura de apropriação que, sob os rótulos de literatura conceitual e escrita não-criativa, tem sido interpretada por críticos como Goldsmith (2011), Perloff (2013) e, no contexto brasileiro, Villa-Forte (2019) como característica do mundo interligado pelas redes neste primeiro quarto do século XXI.

O presente trabalho pretende investigar, assim, as peculiaridades que caracterizam o trabalho da citação mobilizado pelo compositor (e escritor e artista plástico etc.) estadunidense John Cage, frequentemente citado como precursor da escrita apropriativa contemporânea por Goldsmith (2011). Trata-se, nas próprias palavras de Cage, de uma "escrita através [writing through]", recurso fundamental do que denominamos os textospreparados desse autor: aplicando as regras do mesóstico ou operações aleatórias (chance operations), o compositor produzia um novo texto a partir de palavras, às vezes apenas sílabas e letras, de um texto fonte, no qual o sentido e a sintaxe do original comparecem às vezes apenas residualmente. Cabe destacar que o trabalho de citação enfocado aqui não é fundamentalmente aquele das composições musicais cageanas, como, por exemplo, Imaginary landscape No 5 (1952), para 42 gravações preexistentes distintas, mas sim o dos seus textos ${ }^{1}$. Em certo sentido, tal fato nada tem de singular, visto que falar das atividades do compositor americano nos âmbitos da música, do pensamento social, das artes visuais - dos inúmeros interesses, em suma, desse criador extraordinariamente multifacetado - implica quase sempre falar também da sua escrita. Patterson (2002b, p. 85) lembra que

1 Por oposição a certa indistinção no âmbito da escrita, as práticas da citação e da colagem divergem fortemente no âmbito das artes plásticas e da música, a colagem denotando a presença literal de material heterogêneo em uma obra por oposição à alusão mimética a uma fonte no caso da citação. Sobre a noção de colagem no âmbito da música experimental, ver Henrique Iwao Jardim da Silveira (2012). 
[...] seus primeiros vinte anos de ensaios e conferências se tornaram acessíveis ao público em geral somente a partir do início dos anos 1960, concomitantemente ou mesmo antes da publicação da maior parte das suas composições. Historicamente, portanto, seus trabalhos em prosa não foram lidos pelos interessados na sua obra como curiosidades secundárias, tendo, na verdade, servido como porta de entrada para o universo do compositor, algumas vezes muito antes da oportunidade concreta de ouvir alguma das suas composições. ${ }^{2}$

É também através das suas palavras, como propõe novamente Patterson (2002b, p. 99), que "Cage torna-se um foco para as artes como um todo [creative arts in general], a partir da sua ascensão ao posto de guru das vanguardas [avant-garde guru-hood] no início dos anos 1960, devido em larga medida à publicação de Silence e A year from monday". Mas ao contrário, por exemplo, dos Futuristas da belle époque - que alcançaram notoriedade internacional através dos seus famigerados manifestos antes de produzir qualquer obra capaz de satisfazer as exigências ali contidas ${ }^{3}$-, os textos reunidos em Silence (1961) e A year from monday (1967), assim como nas coletâneas posteriores que seguiram o modelo dessas, fazem parte da própria obra cageana. Na introdução de Silence, Cage (2011, p. ix) nos conta que

Por vinte anos tenho escrito artigos e apresentado conferências. Muitos desses trabalhos são formalmente inusitados - especialmente as conferências - posto que neles empreguei métodos de composição análogos àqueles empregados nas minhas composições musicais. Frequentemente minha intenção foi a de dizer o que tinha a dizer de forma a exemplificá-lo; isto permitiria ao ouvinte experimentar o que eu tinha a dizer ao invés de apenas ouvir algo a respeito. $\mathrm{O}$ que significa que, estando envolvido em uma variedade de atividades, tento introduzir em cada uma delas elementos convencionalmente limitados a uma ou mais de outras.

2 Todas as traduções a partir de trabalhos citados em inglês na bibliografia são de nossa autoria. 3 Cf. PERLOFF, 1993a, p. 151-169. 
A espécie de corrosão interna da teoria musical - ou, talvez, mesmo da teoria lato sensu - enquanto gênero textual que encontramos em Cage pode ser pensada como análoga a uma das suas invenções mais importantes: o piano preparado. Mais do que um (quase) novo instrumento ou um conjunto de novas sonoridades, trata-se do gesto que inaugura uma nova relação entre escrita musical e som resultante, marcada pela indeterminação. Em artigo retrospectivo de 1972, um dos poucos textos convencionais publicado no livro Empty Words (1979), Cage descreve como as peculiaridades do piano preparado impactaram a sua concepção de identidade dos sons.

Quando comecei a colocar objetos em meio às cordas do piano, foi com o desejo de possuir sons (ser capaz de repeti-los). Mas, quando a música saiu da minha casa e passou de piano a piano e de pianista a pianista, tornou-se evidente não apenas que dois pianistas serão essencialmente diferentes um do outro, mas igualmente que dois pianos nunca serão idênticos. Ao invés da possibilidade de repetição, nos confrontamos na vida com as qualidades e características únicas de cada situação. (CAGE, 2009b, p. 8)

O que poderia ser visto como um pormenor anedótico será desenvolvido por Cage de maneira extremamente radical resultando em trabalhos que desembocaram na concepção de obra aberta ${ }^{4}$. Yasunao

$4 \quad$ Quando Eco (1991, p. 37-38) introduz em 1958 seu conceito de obra aberta, alude no início da argumentação ao exemplo de algumas composições da música contemporânea pós-serialista - nominalmente o Klavierstück XI de Karlheinz Stockhausen, a Sequenza per flauto, de Luciano Berio, Trocas, de Henri Pousseur e a Terceira sonata para piano, de Pierre Boulez - que concedem um grau de autonomia particularmente grande ao intérprete musical, chamado agora a interferir na própria estrutura da obra. Tal convite, na forma como aparece no texto de Eco, parece detonar a reflexão a respeito da abertura inerente às múltiplas formas artísticas. As peças musicais citadas por Eco têm outro ponto em comum: a influência direta (como mostra David Nicholls (2002, p. 47-49), no caso da Terceira sonata de Boulez e Klavierstück $X I$ de Stockhausen) ou indireta, da chamada escola nova-iorquina de composição musical designação com a qual se costuma referir ao grupo formado pelos compositores John Cage, Morton Feldman, Earle Brown e Christian Wolff. 
Tone desenvolve a ruptura representada pelo piano preparado em chave incidentalmente linguística:

A "invenção" cageana do piano preparado, que à primeira vista aparece como uma mera inovação técnica, gerou a ruptura entre as notas (o conceito de frequência sonora no âmbito da partitura) e as imagens auditivas concretas (o que a frequência representa), o que implica a ruptura entre significante (nota) e significado (a vibração sonora executada). Assim, uma nota escrita enquanto escrita (écriture) e enquanto conceito de nota - significado (signifié) - através dessa série de eventos coloca em questão o sistema tonal como um todo.

Saussure escreveu que "Língua (langue) e escrita (écriture) são dois sistemas de signos distintos; o segundo existindo com o único propósito de representar o primeiro". O que é garantidamente verdadeiro quando um pianista executa uma partitura convencional, que pressupõe que uma nota escrita, enquanto escrita (écriture), seja transformada em som, um passo a cada vez, até que a cadeia de significantes inteira seja transformada na idealidade da música. Tal sistema representativo não pode ser aplicado ao piano preparado. O piano preparado cageano se apresenta como um problema de significação [a problem of signs], e esse era um problema característico dos anos 1960 [a 1960 s problem par excellence]. Um forte laço entre o sistema tonal e o teclado do piano se quebrou; e, por fim, a partitura cageana para piano preparado se transformou em indicações para a ação. Em outras palavras, embora uma nota na partitura indicasse uma certa frequência, o som executado estava longe da representação da nota, o que significava que na realidade não se pedia ao pianista para executar um som, mas que agisse acionando uma certa tecla do teclado. Disso resulta que o som é apenas ex post facto, estando sua performance apenas a alguns passos de distância da "música de eventos" ou do happening. (TONE, 2003, p. 13-14)

É a partir do piano preparado, portanto, que a relação entre a partitura convencional e a realização sonora de uma determinada peça deixa de ser passível de ser pensada de maneira não problemática através da relação saussuriana entre significante e significado. A preparação 
expõe o caráter ficcional da relação entre notação e sonoridade. Traz à tona a "suspension of disbelief" implícita na equação entre sons e notas. Explicita, por fim, a arbitrariedade da exclusão do âmbito da música de sons que não se enquadram no formato eleito como princípio notacional da música do Ocidente: a nota, simultaneamente marca individualizável na partitura e subcategoria dos fenômenos sonoros caracterizado por uma determinada frequência e estrutura espectral (cujo modelo é a série harmônica) via de regra estável entre seu ataque inicial e seu decaimento definitivo. Se nas composições cageanas para piano preparado dos anos 1940 a notação das peças continua a se dar no âmbito gráfico da partitura tradicional, tal notação já não funciona mais como registro de um conjunto de sons repetíveis. Tendo reintroduzido a questão da escrita no cerne das preocupações composicionais, a preparação do piano indica o caminho para a investigação da natureza operacional e gráfica da notação musical, empreendida por Cage e demais compositores da escola nova-iorquina dos anos 1950. Parte desses novos construtos gráficos de notação musical serão apreciados inclusive a partir de certo interesse visual autônomo, como no caso da partitura do Concerto para Piano e Orquestra que chegou a ser exibida no ano de 1958 na Stable Gallery de Nova York ${ }^{5}$.

Dado o interesse pela subversão do modelo saussuriano da linguagem, se poderia supor que - tendo o projeto musical de Cage desde os anos 1930 como um dos seus objetivos a inclusão dos sons "não musicais" na música - seu projeto textual fosse marcado pela introdução do nãosentido no universo das palavras. No entanto, não se trata de algo que possa ser postulado de maneira unívoca, ainda que essa seja uma possibilidade tanto descrita como executada em determinados textos. A leitura proposta aqui toma como modelo o piano preparado - e não, digamos, as plantas amplificadas que Cage utilizou nos anos 1970 -, exatamente pelo caráter limítrofe do primeiro. Apesar de não funcionarem mais como linguagem fechada, as notas continuam presentes no teclado do piano preparado. E, semelhantemente, significados, ideias, narrativa e sintaxe permanecem ao

Cf. BROWN, 2002, p. 111 
menos de maneira residual na ampla maioria dos textos que Cage compôs a partir de procedimentos musicais. A diferença - como entre "as pessoas que são pessoas" e "as montanhas que são montanhas" tanto antes quanto depois de ter-se estudado Zen, na anedota do mestre Suzuki, citada por Cage (2011, p. 95-96) - talvez seja apenas que de alguma maneira nos encontremos ali "com os pés um pouco fora do chão".

É nesse sentido que David Patterson retoma a metáfora do piano preparado. Na sua análise, a forma como Cage utiliza ideias, conceitos e concepções de inúmeras fontes acabaria por produzir uma "retórica preparada”: o procedimento cageano da apropriação arranca as ideias pela raiz, as separa das próprias raízes (contextos originais). Garante assim que as ideias apareçam na sua escrita "com os pés um pouco fora do chão", ainda que nem sempre "sem pé nem cabeça".

Podemos pensar a articulação entre a textualidade preparada e a retórica preparada, a que se refere Patterson, através da descrição que Cage propõe do seu mais importante ciclo de peças para piano preparado dos anos 1940: as Sonatas e Interlúdios (1946-48). Na primeira conferência de Composition as process, I.Changes, o compositor descreve como organizou de maneira rigidamente matemática a estrutura da peça, escolhendo, porém, seu material - as preparações das quais resultará a sonoridade geral - , "como quem escolhe conchas à beira da praia" (CAGE, 2011, p. 19). Da mesma forma, na preparação do texto encontramos dispositivos metódicos, sejam eles estruturas fixas ou procedimentos aleatórios (chance operations), que organizam, encadeiam e fragmentam de maneira não hierárquica (as ideias, temas e narrativas não aparecem umas em consequência das outras), uma peculiar coleção de assuntos, ideias e narrativas cujo único ponto comum é constituírem interesses do compositor, o repertório de sua retórica preparada - cogumelos, Zen Budismo, anedotas do cotidiano, comentário social, além naturalmente de música, sons, arte em geral. A preparação textual também contribui para a preparação retórica, posto que a fragmentação textual - assim como a contínua mistura entre relevância e irrelevância dela resultante - tende a desarmar a leitura analítica, o pensamento lógico que busque corroborar 
ou refutar as ideias ali expostas. As conferências continuam conferências, assim como o piano continua um piano; a preparação garante, porém, que tudo se passe "com os pés um pouco fora do chão".

Podemos supor que, ao buscar imergir o leitor no universo cageano ao invés de convencê-lo através de argumentos organizados de maneira convencional, a escrita do compositor estadunidense visava fundamentalmente superar a resistência de um meio musical hostil a suas propostas ou, até mesmo, de uma sociedade hostil à sua pessoa. É de fato tal característica que torna seus textos, que a princípio poderiam interessar apenas a músicos, tão atraentes. Sua potência, no entanto, resulta igualmente em uma memória monumental particularmente opaca: a forma como são construídos reforça a tentação contínua de ler Cage como alguém desvinculado de contextos específicos, ou mesmo de ignorar que sua extraordinária releitura de variadíssimas fontes se assemelha, em parte, à natureza colecionista etnocêntrica dos riquíssimos museus que a era do Imperialismo legou à Europa e também aos EUA.

Como visto, a revolução musical cageana, inaugurada pelo piano preparado, se baseia em uma transformação da relação entre a escrita musical, sua performance (leitura musical) e o resultado sonoro desse processo. De maneira análoga, a escrita cageana se volta justamente sobre o processo de leitura. $\mathrm{O}$ ato mesmo de ler é arrancado do consenso que define a leitura silenciosa como padrão para a obra literária e que coloca uma leitura supostamente expressiva de matriz dramática/teatral como padrão único de performance literária oral. $\mathrm{O}$ orador, conferencista, contador de casos - já que parece impróprio descrever tal figura como bardo ou aedo - torna-se ao mesmo tempo instrumentista e instrumento, executando uma composição por vezes indissociavelmente verbal e sonora (musical). Afetada a leitura enquanto mecânica de decodificação, desloca-se igualmente a leitura enquanto produção de sentido: na maior parte das conferências, posições e proposições - musicais, artísticas, literárias, políticas etc. - são apresentadas, mas não à maneira do tratado ou mesmo do manifesto. $\mathrm{O}$ que se parece buscar é a lógica da imersão, algo próximo do ritual, do encantamento. E para tanto o compositor lança 
mão continuamente de toda espécie de repetição - ao mesmo tempo "inexistente" e matéria-prima da escrita tanto para Gertrude Stein quanto para Cage e análoga ao silêncio na música desse.

Dentre as múltiplas formas de repetição que encontramos na escrita cageana, cabe destacar primeiramente a presença constante justamente de recortes de textos anteriores, tanto de própria lavra como de terceiros, inclusive porque, como coloca Compagnon (1996, p.17), “Toda citação é primeiro uma leitura”. Mas mesmo a citação em Cage é preparada, subvertida. Podemos tomar como modelo a descrição que Compagnon (1996, p. 13) propõe do ato de citar:

Quando cito, extraio, mutilo, desenraízo. Há um objeto diante de mim, um texto que li, que leio; e o curso da minha leitura se interrompe numa frase. Volto atrás, re-leio. A frase relida torna-se fórmula autônoma dentro do texto. A releitura a desliga do que lhe é anterior e do que lhe é posterior. $\mathrm{O}$ fragmento escolhido converte-se ele mesmo em texto, não mais fragmento de texto, membro de frase ou de discurso, mas trecho escolhido, membro amputado; ainda não o enxerto, mas já órgão recortado e posto em reserva. Porque minha leitura não é monótona nem unificadora; ela faz explodir o texto, desmonta-o, dispersa-o.

Como previsto pelo teórico francês, a citação cageana extrai, mutila, desenraíza; desliga o fragmento do que lhe é anterior e posterior, transformando-o em texto autônomo; explode, desmonta, dispersa um texto outro. Mas a leitura cageana, recorrendo a procedimentos aleatórios (chance operations), não é atraída - ou melhor, solicitada, para usarmos a terminologia de Compagnon - por uma frase, uma combinação de palavras ou uma ideia. Delegando a leitura a um método, muitas vezes o I ching, totalmente alheio ao desejo e ao gosto do autor, não se pode falar exatamente de "trecho escolhido". Baseada no acaso, a citação sem solicitação se torna, como prevê novamente Compagnon (1996, p. 22), maquinal e gratuita. A citação cageana desconhece "a alegria do artesão consciencioso ao se separar de um produto acabado que não traz o traço 
de seu trabalho", à qual se refere o teórico francês (p. 28), ao falar da acomodação de uma citação em seu texto de destino.

Mantendo a marca do corte maquinal no texto de origem - que se revela em frases truncadas, pensamentos incompletos, mudanças súbitas de assunto e até mesmo palavras fragmentadas em sílabas ou letras -, a escrita cageana opta por um modelo visual de citação: a colagem modernista. Segundo Perloff (1993a, p. 102), o procedimento iniciado por Braque e Picasso e rapidamente difundido pela rede europeia de artistas de vanguarda às portas da Primeira Guerra Mundial se diferencia das "colações" realizadas em outros contextos "pelo fato de que sempre implica a transferência de materiais de um contexto para outro, ainda que o contexto original não possa ser apagado". Como afirma um manifesto do Grupo $\mathrm{Mu}^{6}$, citado pela autora, o "estratagema da colagem consiste também em nunca suprimir inteiramente a alteridade desses elementos reunidos em uma composição temporária”.

Considerando a colagem como procedimento de escrita, cabe partir talvez da obra de Tristan Tzara conhecida como Para fazer um poema dadaísta, na verdade uma das seções do Dada manifesto sobre o amor débil e o amor amargo de 1920 (TZARA, 1987, p. 37-47). Trata-se ali de um conjunto de instruções, proposição de um processo que, mesmo se materializando parcialmente em certas colagens dadaístas e "pinturas de palavras" futuristas dos anos 1910-1920, será utilizado de forma mais sistemática nos cut-ups textuais que Brion Gysin e William S. Burroughs produziram a partir da virada dos anos 1960: trechos recortados de algum material escrito (um jornal, no caso de Tzara) são recombinados de maneira aleatória ou nem tanto para formarem um novo texto. Goldsmith (2011) enfatiza a relação entre tal procedimento e um paradigma tipográfico da escrita, expandido posteriormente pelo advento da xerografia, no qual se manipula o texto impresso por meio de um procedimento literal de recortes e colagens, em contraste com o caráter metafórico que o gesto de "recortar" e "colar" assume no meio digital.

Apud PERLOFF, 1993a, p. 102-103. 
Desde seus primórdios, a colagem propriamente dita se apropriou dos materiais - especialmente dos papéis impressos - à mão, o que durante todo o século XX incluiu a figura onipresente do jornal diário. Cage via de regra não utiliza o jornal como material para sua escrita, voltada antes para textos - conchas na praia - que o solicitam enquanto totalidade, não enquanto fragmento específico. Ele elege, porém, o jornal como modelo de leitura. Na bula de Indeterminacy, o compositor sugere que os casos espalhados entre os textos principais de Silence sejam lidos “da maneira e nas situações em que alguém lê jornais $[\ldots]$ quando o faz sem um objetivo: isto é, saltando aqui e ali e respondendo ao mesmo tempo aos acontecimentos e sons do ambiente." (CAGE, 2011, p. 261) Ideia que se repete - atribuída agora ao guru estético-tecnológico dos anos 1960, Marshall McLuhan - como um dos fragmentos retangulares que compõem Seriously comma (1966), incluído em A year from Monday: "McLuhan insiste na capa do jornal como o tipo de existência atual. Lendo, não lemos mais sistematicamente (concluindo cada coluna, ou mesmo passando a página para concluir um artigo): saltamos." (CAGE, 2009a, p. 26)

Ideia repetida novamente, dessa vez em termos de paralelo entre a escrita verbal e a escrita musical, como em um dos casos de How to pass, kick, fall, and run, também em A year from Monday:

Você já reparou como se lê um jornal? Saltando, deixando artigos não lidos, ou apenas parcialmente lidos, desviando aqui e ali. De forma alguma o modo como se lê Bach em público, mas precisamente o modo como se lê em público Duo II for pianists de Christian Wolff. (CAGE, 2009a, p. 136)

A grande questão com a qual se depara a escrita cageana é, portanto, a seguinte: como reproduzir na escrita o movimento errático da leitura que salta? Como obrigar o leitor - paradoxo da obra aberta - a não ler linearmente? A construção de um texto a partir de outro navegado por procedimentos aleatórios (chance operations) é uma das respostas encontradas por Cage. Resposta em parte antecipada pelas leituras 
divinatórias - abrindo um livro ao acaso -, praticadas desde a antiguidade tardia em textos de Virgílio e na Bíblia (FISCHER, 2006) e vinculadas à possibilidade de acessar inteiramente uma obra de maneira não linear proporcionada pelo códice, por oposição ao livro em forma de rolo.

Outra estratégia utilizada por Cage é fragmentar um fio discursivo e/ou narrativo ao longo de todo um texto, interpolando-o com vários outros, como talvez o faça o leitor de jornais. $\mathrm{O}$ caso da condessa que tem uma crise súbita de diarreia, por exemplo, encontra-se disperso ao longo de sete páginas em meio a um fragmento de Diary: How to improve the world (You will only make matters worse), incluído em M (CAGE, 1998, p. 103-110). Devido às características peculiares do koan cageano ${ }^{7}$, ao final de cada fragmento poderíamos encontrar o final da história - visto que não se espera ali nem por um fim convencional nem por um arremate (punch line) -, mas algumas linhas adiante, talvez na página seguinte, reencontramos a narrativa que se torna a cada volta mais inconclusa e mais absurda. Todos os outros pensamentos e histórias que compõem o texto, relevantes e/ou irrelevantes para o tema central do "melhoramento do mundo", aparecem então como o meio no qual o caso da condessa se encontra suspenso, demonstrando novamente a não contenção (unimpededness) e interpenetração reivindicadas por Cage.

Retornando à leitura divinatória ao acaso, cabe observar que, se ali o fragmento é encontrado sem a solicitação prevista pela teoria da citação de Compagnon, as obras utilizadas, no entanto, não são obras quaisquer. Igualmente, os procedimentos cageanos eliminam a solicitação no nível micro, mas, ao escolher o texto que será devassado como um container por suas operações aleatórias, Cage estará novamente recolhendo conchas

\footnotetext{
"O koan consiste em um tema ou afirmação dado a um estudante do Zen para que o solucione, conduzindo-o à iluminação espiritual. Na sua forma budista clássica, a um monge iniciante seria apresentada uma questão ou problema ilógico pelo dirigente do mosteiro, que avaliaria então a resposta dada. Se o noviço batalhasse para construir uma resposta usando o pensamento lógico, ele falharia; se absorvesse a verdade contida no koan de maneira intuitiva e não-discursiva, ele passaria. A irracionalidade intrínseca ao koan seria assim "resolvida" pela iluminação do satori. Na versão cageana, porém, a ênfase se dá menos no satori do que na irracionalidade ou absurdo em si." (PERLOFF, 1993b, p. 309)
} 
na praia. Os textos através dos quais Cage lê/escreve - do radicalismo protoanarquista de Thoreau, ao espiritualismo indiano compilado para olhos ocidentais (ou ocidentalizados), do Evangelho de Sri Ramakrishna à literatura modernista de vanguarda de Ezra Pound e James Joyce correspondem a um recorte nada "ao acaso" dentre a diversidade de leituras possíveis em meados do século XX. Mesmo os casos trazidos "diretamente da vida" contemplam o cotidiano de um grupo bastante peculiar formado basicamente de artistas plásticos, músicos, dançarinos e micologistas amadores, o círculo social frequentado de maneira nem um pouco aleatória pelo compositor estadunidense. Nesse sentido cabe talvez pensar Diary: How to improve the world ... menos como um diário íntimo e mais como um jornal diário, como a crônica contínua do universo e das preocupações do círculo cageano.

Quando Marshall McLuhan reivindica a capa do jornal como paradigma da contemporaneidade, ele evoca a famosa afirmação de Hegel (apud ANDERSON, 2008, p. 68) de que o jornal seria para o homem moderno o substituto das preces matinais. Benedict Anderson (2008) argumenta que o jornal diário seria um dos modelos fundamentais do tempo homogêneo e vazio e a sensação de uma simultaneidade anônima que funda as comunidades imaginárias contemporâneas, a começar pelas nações. Adepto do tempo homogêneo e vazio do relógio, onde tudo pode acontecer - por oposição tanto ao ritmo orgânico do pé-que-bate-nochão quanto do tempo métrico do metrônomo -, Cage não enfatiza, no entanto, a ideia de nação como tal (e nisso ele está em desacordo com uma fração importante dos compositores modernos americanos da sua geração - como, por exemplo, Aaron Copland). Em direta oposição ao nacionalismo, $A$ year from monday e $M$ abrem com a seguinte dedicatória:

Para nós e todos os que nos odeiam, que os E.U.A possam se tornar apenas mais uma parte do mundo, nada mais, nada menos. (CAGE, 2009a, p. vii; CAGE, 1998, p. v) 
Seu internacionalismo, porém, é a expansão ao nível global do tempo homogêneo e vazio: um dos temas recorrentes dos dois primeiros fragmentos de Diary: How to improve the world ... é a busca por descobrir quantos serviços globais (global services) estavam então em funcionamento. Cage via a existência de tais serviços com um indício de uma integração global capaz de extinguir os estados nacionais e, consequentemente, as guerras por eles produzidas. Sem dúvida, Cage (2009b, p. 184), que em um texto de 1974 escreveu que "em breve todos, músicos ou não, terão um computador no seu bolso", seria um entusiasta da Web, caso tivesse vivido o suficiente para vê-la em ação. Em um momento anterior da acessibilidade à informação, ele já comemorava no primeiro fragmento de Diary: How to improve the world ... : "livros dos quais se precisava antes eram difíceis de se encontrar. Agora eles saem em edições baratas [paperback]" (CAGE, 2009a, p. 8).

Se o jornal torna a existência simultânea de inúmeros lugares, senão palpável, pelo menos inteligível por meio da ficção que submete todos os acontecimentos a um agora, representado pela data da edição, como propõe novamente Anderson (2008, p. 65), tal simultaneidade para Cage seria expandida pelos novos meios de comunicação eletrônicos e globais. $\mathrm{O}$ universalismo cageano rejeita enfaticamente uma segregação entre os conhecimentos do Ocidente e do Oriente, aproximando por exemplo o Zen Budismo do misticismo gnóstico dos princípios do Cristianismo ${ }^{8}$. Por outro lado, por mais que concebido nos termos mais benévolos, implica também certo expansionismo de uma simultaneidade temporal de raízes claramente ocidentais, como quando Cage (2009b, p. 187) encerra seu artigo de 1974, intitulado The future of music da seguinte forma: "É tempo de apresentar um concerto de música moderna na África. A mudança não é disruptiva. É alegre."

Nesse sentido, podemos observar que nem mesmo o acaso é inocente, que o repertório a ser recortado pelas operações aleatórias reproduz de diversas formas hierarquias e estruturas de poder, para além

$8 \quad$ Cf. CAGE, 2009a, p. 136. 
de toda a boa vontade utópica que Cage injeta em sua poética. Como propõe Alastair Williams (2002, p. 239), se por um lado Cage "antecipa a ideia do museu sem paredes, no qual culturas de diversos tempos e lugares se encontram disponíveis para o presente histórico", por outro "a neutralidade de Cage frente às diversas, às vezes incomensuráveis, visões de mundo oferece pouco subsídio para habitar tal ambiente”. Cabe acrescentar que Cage realiza sua operação de leitura global a partir do espaço que se tornava naquele momento hegemônico no campo artístico mundial, Nova York.

De novo nos encontramos na encruzilhada entre o texto preparado e a retórica preparada: apagando o nome e o contexto que localizariam suas matérias-primas discursivas, a lógica apropriativa do texto cageano subverte a lógica da propriedade intelectual ocidental, mas, na sua neutralidade programática, corre também o risco de emular o gesto anômico do saque colonialista. $\mathrm{O}$ fato é que, preparando de múltiplas maneiras seus textos, Cage limita os procedimentos do que Compagnon chama enxerto, ou seja, a acomodação de uma citação no texto de destino. Com exceção de alguns artigos - como Erik Satie, no qual as citações do compositor francês se encontram diagramadas em retângulos alinhados à esquerda, enquanto as "respostas" de Cage em retângulos alinhados à direita e Mosaic, no qual as citações de Schoenberg estão impressas em itálicos -, não é usual que a escrita do compositor apresente formas de diferenciar o que é e o que não é citação, ou seja, aspas ou recursos semelhantes. Aspas que normalmente, mais uma vez nos informa Compagnon (1996, p. 39), operariam "uma sutil divisão entre sujeitos e assinala[ria]m o lugar em que a silhueta do sujeito da citação se mostra em retirada, como uma sombra chinesa”. No caso do compositor estadunidense - que rejeita as noções de começo, meio e fim exatamente por derivarem de "uma noção de sujeito [a sense of self] que separa a si mesmo do que considera ser o resto da existência" (CAGE, 2011, p. 134) - tal divisão talvez estivesse por demais ligada à ideia de propriedade. Em um trecho de Lecture on nothing, repetido integralmente na Juilliard lecture (2009a, p. 106), Cage propõe a seguinte reflexão steiniana sobre passado e repetição: 
a constata-

(posto que não possu- ímos)

Nós

a qualquer momento

que era nosso, mas

por- tanto

e, de que não possuímos

nada

sendo assim,

passado:

parecer ser

repetição?

está livre é um deleite

não precisamos temer perdas

ele se foi;

e ser o presente

Só se pensássemos

assim como nós

(CAGE, 2011, p. 110)

Se o passado não pertence a ninguém e não pode ser repetido, a referência a uma autoria não se coloca como obrigatória para a citação, o sujeito que cita se mistura ao sujeito cujo texto é citado. Um fragmento de Diary: How to improve... de 1968, publicado em M, cita o poeta Robert Duncan, colega de Cage no Black Mountain College, falando incidentalmente sobre aspas e autoria:

Duncan me disse que sua poesia vinha [was picked up] de outras pessoas. A única ocasião em que ele tinha, disse, vontade de usar aspas era quando as palavras que ele escrevia eram suas. (CAGE, 1998, p. 13)

Nada mais relevante para a presente discussão do que a forma como Compagnon (1996, p. 39) compara as aspas, que tentam "circunscrever a enunciação e seus níveis em territórios ou em paradas indicadoras”, com "as indicações de ritmo, os vetores de interpretação que o compositor propõe ao executante” em uma partitura musical. Tais são exatamente os elementos da notação musical que o projeto cageano da música indeterminada em relação à sua execução pretende eliminar. 
O passado, as palavras e as ideias não pertenceriam, dessa forma, a ninguém. Cage (1998, p. 15): "Gastei várias horas/folheando um livro, tentando/encontrar a ideia que tinha tirado dele./Não consegui. Ainda tenho a ideia”. Mesmo pensando estritamente na lógica da escrita cageana, trata-se de uma simplificação ou talvez um horizonte utópico. Boa parte das vezes, Cage cita literalmente, palavra por palavra, o que supõe a presença - ainda que recopiada, fragmentada, etc. - do texto original. Em certos textos, a bula assume a função das aspas subtraídas do corpo do texto, informando autores, fontes e até mesmo os detentores do respectivo copyright. Em uma fórmula paralela ao "Como melhorar o mundo (você só vai piorar as coisas)” que qualifica ironicamente a série Diary, Cage (2009a, p. 17) chega a escrever em um dos fragmentos da própria: "livre-se do copyright (esse texto tem copyright)". Optando por escancarar algumas das contradições resultantes da sua posição, nas palavras de Williams (2002, p. 239-240):

Cage parece ter tido uma noção intuitiva de como trabalhar com tais discursos em um nível institucional. Nesse aspecto, ele tem muito em comum, e possivelmente inspirou, artistas contemporâneos, como Cindy Sherman, que trabalham com códigos [codes] ao invés de materiais tradicionais. E é certamente verdade que Cage sempre foi mais amplamente aceito por artistas plásticos do que por músicos. No nível institucional, práticas culturais se tornam reflexivas porque, ao invés de operarem dentro de limites, questionam tudo aquilo que define tais fronteiras e limitações. Como muitos artistas [practitioners] e teóricos contemporâneos, Cage também possuía uma noção acurada para o fato de que suas atividades eram performativas: que fazendo as coisas de determinada maneira, elas redefiniam os $[. .$.$] discursos.$

Observamos na escrita cageana, portanto, um jogo duplo no âmbito da citação. No corpo do texto, a propriedade intelectual e textual é questionada tanto tematicamente quanto como procedimento de escrita (por meio da ausência de referência a autoria, omissão das aspas e recorte maquinal de textos anteriores), seguindo a proposta cageana de "de dizer 
o que tinha a dizer de forma a exemplificá-lo”. Por outro lado, toda a perigrafia das coletâneas, a começar pelo que poderíamos denominar as bulas de cada texto ${ }^{9}$, escancara tais procedimentos, cancelando em parte o anonimato da citação e chamando a atenção às responsabilidades legais e as restrições jurídicas e culturais de uma sociedade no qual as ideias, as palavras e os sons são sim considerados propriedade. Como $A$ fonte de Marcel Duchamp, mentor e amigo de Cage, os textos do compositor tornam visível o contexto que os possibilita e, assim, delimita a sua liberdade aparentemente total. Ou seja, se por um lado, como descreve Williams (2002, p. 231), os "procedimentos automatizados dissolvem a intenção autoral e a significação cultural sedimentada [encultured meaning]", por outro, só reconhecemos o texto cageano como um emaranhado de citações primeiramente pelo fato de assim sermos informados a respeito de como são construídos pela sua perigrafia.

A citação, em um regime de textualidade totalmente destituído de propriedade, seria anônima, sem nada que a marcasse como repetição; indistinguível, de fato, do que chamamos plágio. Seria invisível. Cage parece parar sempre um pouco antes, indicando na maior parte das vezes que algo veio de algum lugar, ao mesmo tempo que obstrui a recuperação de tal trajetória. Em Rhythm etc. lemos o seguinte trecho:

(Ele trabalhou por vários anos e enquanto trabalhava sua técnica melhorou, mas ele preferiu manter suas inaptidões, para revelar, assim,

As instruções adicionais da partitura, denominadas "bula" na prática musical brasileira, complementam aquilo que a notação convencional não tem como informar, suplementando uma escrita desenvolvida para registrar uma outra linguagem musical e que subitamente deixou de ser evidente. Pensar os paratextos cageanos como bulas, molduras necessárias para que a dimensão gráfica do texto seja interpretável enquanto som, não esgota, porém, seu interesse. Para além das instruções adicionais, encontramos ali estampadas também com frequência as estratégias que presidiram a sua construção, referências às fontes utilizadas, anedotas e comentários mil em torno de um texto que, explicado em seus mínimos detalhes, mantém quase sempre o seu mistério. Como diria Compagnon (1996, p. 70) a respeito da perigrafia em geral, temos aqui uma "zona intermediária entre o fora do texto e o texto", "uma cenografia que coloca o texto em perspectiva, cujo centro é o autor”. Ao invés de encerrar e localizar um texto, restringir sua abertura, as bulas parecem multiplicá-lo. 
não algo perfeito, mas algo que mostrasse que ele estava vivo enquanto produzia aquilo.) E, no entanto, eu sei quando vejo algo que ao menos faz os signos da simetria que estou em um lugar onde medidas não têm mais significância real. (Como suas bandeiras e alvos, alfabetos e latas de cerveja.) (CAGE, 2009a, p. 123.)

Bandeiras, alvos, alfabetos, latas de cerveja: trata-se de Jasper Johns, artista plástico amigo de Cage, ao qual o compositor dedica um dos textos de $A$ year from monday. Mas no texto que inclui o trecho citado acima, não encontramos seu nome, nem mesmo na bula. É apenas através do recurso metonímico a algumas das suas obras emblemáticas que podemos reconhecê-lo. Recurso indisponível para um trecho como "Ele veio/ avisado; e então/outro e me agradeceu pelo / Mallarmé e o trabalho; e então/eu espirrei” que lemos em uma das quatro camadas de texto sobrepostas de Where are we going ? and what are we doing?(CAGE, 2011, p. 241). O efeito, no entanto, dada a lógica do texto cageano, é de que nesse trecho enigmático ele se refira a algum acontecimento real, de que de alguma forma não se trata de uma narrativa estritamente ficcional.

Como propõe Patterson, cabe menos seguir cada uma dessas pistas em busca de fontes ou origens do que compreender o papel que tais "objetos achados" - ideias, narrativas, frases e palavras readymade cumprem no âmbito da escrita cageana:

a compreensão das palavras de Cage, seja em prosa, poema ou entrevista, é uma "arte para iniciados" ['insider art'], e o maior desafio à sua compreensão reside em traduzir ou decodificar a pletora de empréstimos retóricos que aparecem ali. Em essência, tais empréstimos constituem os "objetos achados" da prosa cageana, e são esteticamente provocadores na sua habilidade de disparar uma abundância de associações conceituais. Por conta da conexão intencionalmente frágil que tais empréstimos retóricos mantêm com suas funções e/ou contextos originais. Em última instância, as perspectivas idiossincráticas de Cage, e as formas em que seu uso de tais empréstimos diverge do contexto original são muito mais interessantes e informativas que a aderência ao espírito ou o sentido original de tais apropriações. (PATTERSON, 2002b, p. 95) 
Uma das apropriações mais reiteradas de Cage consiste na seguinte afirmação encontrada em Ananda Coomaraswamy: "A arte é a imitação da natureza em sua maneira de operação". Alusões, variações, assim como citações literais dessa frase, aparecem aos montes nos escritos cageanos, cinco vezes ao longo de Silence (CAGE, 2011, p. 9;100;155;173;194), três em A year from Monday (CAGE, 2009a, p. 18;51;75). Trata-se de uma pedra de toque da retórica de Cage e em apenas duas das ocorrências citadas, uma em cada coletânea, sua autoria é creditada a Coomaraswamy. A potência da afirmação se encontra na forma como a ideia profundamente tradicional da arte como imitação da natureza, cuja lógica nunca se ajustou muito bem à música, é transformada em uma defesa da arte de vanguarda do século XX. Segundo Cage (2009a), devido aos avanços da ciência é a própria compreensão da maneira de operação da natureza que muda, obrigando a transformações no fazer artístico.

Como demonstra Patterson (2002a, p. 44-48), Ananda Coomaraswamy (1877-1947) dificilmente se reconheceria nas referências de Cage. Erudito ceilonês de nacionalidade Tâmil, Coomaraswamy foi um dos pioneiros da divulgação das múltiplas formas artísticas do subcontinente indiano na Europa e nos EUA. Seu livro The transformation of nature in art, de 1934, do qual Cage extraiu o fragmento citado, consiste, na verdade, em uma defesa da concepção tradicional indiana de arte. Além da ideia da imitação da maneira de operar da natureza, Cage parece ter se reconhecido também na valorização defendida por Coomaraswamy da impessoalidade na arte por oposição à ideia de expressão individual. Mas o argumento central do erudito ceilonês - a ideia de arte como comunicação baseada em uma língua comum, logo em tradição avessa a mudanças - se encontra nos antípodas do pensamento estético de Cage. O compositor estadunidense se apropria, dessa forma, da formulação de Coomaraswamy de maneira ad hoc, não muito distante de "empréstimos" coloniais como o tabaco andino, as redes dos indígenas brasileiros e o xocolatl asteca. $\mathrm{O}$ corte da citação em relação à origem desindividualiza aqui o trabalho de um pesquisador nacionalista capaz de hibridizar concepções indianas e ocidentais, relegando-o à rubrica indistinta de um suposto "pensamento 
oriental”. Nada mais irônico, assim, do que o fato documentado novamente por Patterson (apud KAHN, 1997, p. 564) de que o lema que Cage adota a partir de Coomaraswamy foi buscado pelo erudito ceilonês não em fontes sul-asiáticas, mas na raiz da cultura europeia ocidental, Santo Agostinho: Ars imitatur naturam in sua operatione.

Sendo a escrita cageana fundamentalmente avessa a classificações, sua afinidade com a poesia é, porém, igualmente incontestável. Nas coletâneas tardias, a partir de $M$ (1973), a possibilidade dos escritos cageanos serem poemas aparece de maneira clara, em especial no caso dos mesósticos. A posição de Cage a respeito da relação dos seus escritos com o campo da literatura é, no entanto, mais ambivalente, como podemos observar em um dos fragmentos de Diary: How to improve the world..., igualmente publicado em $M$ :

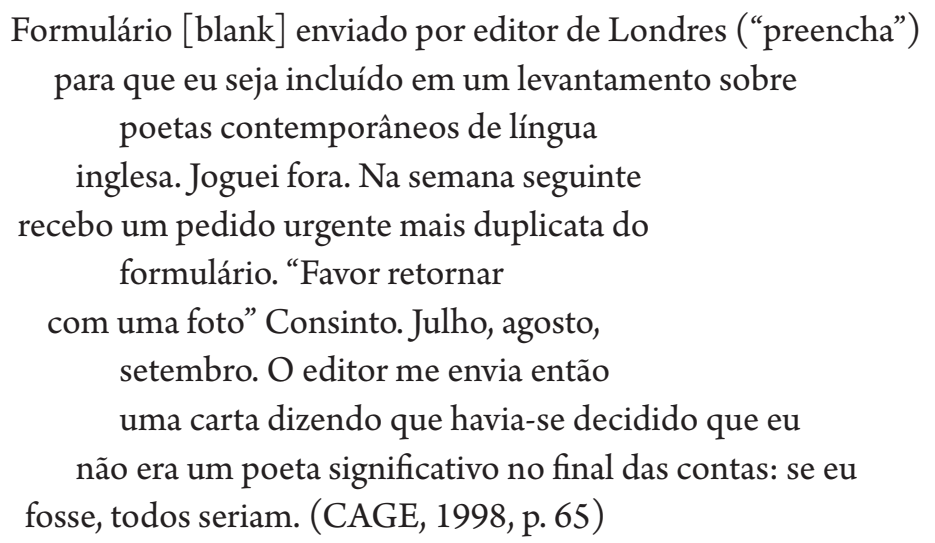

A anedota remete não apenas à dificuldade de classificação da escrita cageana, como a uma ideia frequentemente repetida pelo compositor tanto em textos como em entrevistas: a poesia seria a constatação de que não possuímos nada. Trata-se naturalmente de um lema ajustado a uma estética apropriativa como a de Cage e que, de uma perspectiva brasileira, ressoa necessariamente "a posse contra a propriedade" invocada pelo igualmente escritor-apropriador Oswald de Andrade. 
De toda forma, o interesse pela poesia antecede cronologicamente a própria definição de Cage enquanto músico e compositor. Em entrevista a Irving Sandler, de 1966, ele fala sobre os seus interesses artísticos de juventude nos seguintes termos:

Já não estava na universidade antes dos anos trinta; abandonei o curso. E eu tinha a intenção, primeiramente, de me tornar um escritor, e então fui para a Europa. O que me impressionava em arte era a arte dos anos vinte; em literatura, a revista transition, [James] Joyce e [Gertrude] Stein, [Ezra] Pound e [T. S.] Eliot, e [e. e.] Cummings. (apud KOSTELANETZ, 2003, p. 139)

A produção textual cageana, a princípio motivada pela necessidade de defender teórica e conceitualmente suas criações musicais, acaba por levar o trabalho criativo do compositor de volta às suas origens. Podemos mesmo afirmar que a aparição do mesóstico em $M$ tem o efeito paradoxal de estabilizar a escrita cageana, enquadrá-la definitivamente na categoria "poema", por menos ortodoxa que seja tal qualificação. Apesar de utilizado por alguns poetas importantes na tradição poética ocidental - François Villon, por exemplo - o acróstico, do qual o mesóstico cageano naturalmente deriva, tende a ser na modernidade fundamentalmente uma forma subliterária, mais presente nos exercícios escolares e mesmo na publicidade do que na obra de poetas de renome - talvez por ser considerado um artifício demasiado óbvio ou, como se diria em inglês, um gimmick. Quase no mesmo registro se apresentam os poemas de ocasião, gênero em que se inscrevem os Six Mesostics, que incluem o primeiro deles, em $M$ e os setes avulsos espalhados por Empty Words, todos tendo como eixo o nome de alguém do círculo artístico e/ou pessoal de Cage. Uma segunda variedade de mesósticos pode ser vista como uma expansão dessa. Em 36 Mesostics re and not re Marcel Duchamp, 23 Mesostics re and not re Mark Tobey, de M, e Sixty-one Mesostics re and not re Norman O. Brown, de Empty Words, o nome dos artistas e do scholar mencionados nos respectivos títulos servem de eixo para séries de mesósticos cujos temas são por vezes relacionados, por vezes não relacionados com os 
homenageados ${ }^{10}$. Compostos de uma série de fragmentos líricos escritos por Cage e tendo por única preparação a forma mesóstico, trata-se do material mais facilmente classificável em uma definição minimamente convencional de poema dentre toda a obra escrita do compositor.

Ainda nos anos 1970 e posteriormente até a sua morte, Cage usará o mesóstico também de formas mais radicais, especialmente de modo a escrever através de outros textos. Em textos anteriores ao surgimento do mesóstico a escrita cageana já utilizava, como temos visto, a possibilidade de tal "escrita-através". Mas o estatuto do texto se encontrava ainda distante da estabilidade proporcionada pelo mesóstico. A escrita através dos Cantos e de Finnegans Wake, já conformada em mesósticos, se apresenta, porém, tendencialmente como tão literária quanto seus textos base ${ }^{11}$. No também já mencionado 62 Mesostics re Merce Cunningham, palavras e sílabas retiradas do livro do bailarino e coreógrafo são transformadas pela substituição de letras e dispostas visualmente, segundo o prefácio de $M$, através de setecentos tipos e tamanhos diferentes deLetraset. $\mathrm{O}$ resultado são obras mais próximas da pintura de palavras futurista do que da legibilidade pressuposta convencionalmente por um poema, ainda que, com certo esforço, seja possível tatear uma leitura análoga àquela exigida pelas palavras compostas de Finnegans Wake. Paradoxalmente a radicalização dos recursos visuais e discursivos parece encerrar essa série mais rigidamente na categoria "arte", contrastando com a imprevisibilidade da mistura entre o estético e o mundano que caracteriza, por exemplo, as conferências mais antigas.

A possibilidade mesma de qualificarmos tal encerramento como um fracasso relativo se refere talvez à potência utópica que resiste (para

10 Os re and not re dos títulos se referem à abreviatura de regarding, usada comumente na correspondência de negócios.

11 Os Cantos de Ezra Pound foram utilizados por Cage como matéria-prima para o que talvez possa ser denominado um "mesóstico em prosa" apropriativo publicado na coletânea $X$, de 1983. Junto aos diários de Thoreau, o texto mais utilizado por Cage para tal "escrita através" é Finnegans Wake, de James Joyce. Ao todo, foram cinco trabalhos usando a obra final de Joyce como matéria- prima (cf. MAC LOW, 1999, p. 290-291). 
além de todas as recaídas orientalistas, imperialistas, lineares etc. ali presentes) na proposta cageana de escrever atravessando limites: seja entre o próprio, o alheio e a propriedade privada; entre a música, as artes plásticas e a literatura; entre a poesia, a teoria e a anedota; a arte e a vida, por fim. Dessa forma, não parece exagerado afirmar que os textospreparados do compositor provavelmente continuaram a escrever através de nós, solicitando de maneira intensa a nossa própria citação.

YOUR FEET A LITTLE OF THE GROUND: TEXT-PREPARATION AND QUOTATION IN THE WRITINGS OF JOHN CAGE

Abstract

This article investigates the use of quotation procedures in the written work of the American composer John Cage, in dialogue with the theoretical formulations of Antoine Compagnon. Often characterized as a "writing through", Cagean textual production will be investigated through the notion of prepared text, derived from the idea of prepared rhetorics developed by David Patterson in analogy with the preparations that the composer made for the execution of his works for piano.

KeY wORDs: Quotation. Experimental writing. John Cage.

\section{CON LOS PIES LIGERAMENTE SEPARADOS DEL SUELO: TEXTO-PREPARADO Y CITACIÓN EN LOS ESCRITOS DE JOHN CAGE}

\section{RESUMEN}

El presente trabajo tiene como objetivo investigar el uso de los procedimientos de cita en la obra escrita del compositor estadounidense John Cage, en diálogo con las formulaciones teóricas de Antoine Compagnon. A menudo caracterizada como una "escritura a través", la producción textual cageana será investigada por medio de la noción de texto preparado, derivado de la idea de retórica preparada, desarrollada por David Patterson por analogía con los preparativos que hizo el compositor en el piano para la ejecución de algunas de sus obras.

Palabras Clave: Citación. Escritura experimental. John Cage. 


\section{REFERÊNCIAS}

ANDERSON, Benedict. Comunidades imaginadas: reflexões sobre a origem e a difusão do nacionalismo. São Paulo: Companhia das Letras, 2008.

BROWN, Kathan. Visual art. In: NICHOLLS, David (org.). The Cambridge companion to John Cage. Cambridge: Cambridge University Press, 2002.

CAGE, John. A Year from Monday. Londres, New York: Marion Boyars, 2009a.

CAGE, John. De segunda a um ano: novas conferências e escritos. Rio de Janeiro: Cobogó, 2013.

CAGE, John. Empty Words. Londres, New York: Marion Boyars, 2009b.

CAGE, John. M. London: Marion Boyars, 1998.

CAGE, John. Silence. London, New York: Marion Boyars, 2011.

COMPAGNON, Antoine. O trabalho da citação. Belo Horizonte: Editora UFMG, 1996.

ECO, Umberto. Obra aberta: forma e indeterminação nas poéticas contemporâneas. 8.ed. São Paulo: 1991.

FISCHER, Steven Roger. História da leitura. São Paulo: Editora Unesp, 2006.

GOLDSMITH, Kenneth. Uncreative Writing: managing language in the digital age. Nova Iorque: Columbia University Press, 2011.

KAHN, Douglas. Silence and Silencing. The Musical Quarterly, v. 81, n. 4, p. 556598, 1997.

KOSTELANETZ, Richard (org.). Conversing with Cage. Hove: Psychology Press, 2003.

MAC LOW, Jack. Something about the Writings of John Cage. In: KOSTALANETZ, Richard (org.). Writings about John Cage. Ann Arbor: The University of Michigan Press, 1999.

NICHOLLS, David. Getting Rid of the Glue. In: JOHNSON, Steven. The New York Schools of Music and Visual Arts: John Cage, Morton Feldman, Edgard Varèse, Willem De Kooning, Jasper Johns, Robert Rauschenberg. Nova York: Routledge, 2002. 
PATTERSON, David W. Cage and Asian: history and sources. In: NICHOLLS, David (org.). The Cambridge companion to John Cage. Cambridge: Cambridge University Press, 2002a.

PATTERSON, David W. Words and writings. In: NICHOLLS, David (org.). The Cambridge companion to John Cage. Cambridge: Cambridge University Press, 2002b.

PERLOFF, Marjorie. O gênio não original: poesia por outros meios no novo século. Belo Horizonte: UFMG, 2013.

PERLOFF, Marjorie. O momento futurista: avant-garde, avant-guerre, e a linguagem da ruptura. São Paulo: 1993a.

PERLOFF, Marjorie. The Poetics of Indeterminacy: Rimbaud to cage. Evanston: Northwestern University Press, 1993b.

SILVEIRA, Henrique Iwao Jardim da. Colagem musical na música eletrônica experimental. 2012. 202 f. Dissertação (Mestrado) - Universidade de São Paulo, São Paulo, 2012.

TONE, Yasunao. John Cage and Recording. Leonardo Music Journal, v. 13, p. 11-15, 2003.

TZARA, Tristan. Sete manifestos Dada. Lisboa: Hiena,1987.

VILLA-FORTE, Leonardo. Escrever sem escrever: literatura e apropriação no século XXI. Belo Horizonte: Relicário, 2019.

WILLIAMS, Alastair. Cage and Postmodernism. In: NICHOLLS, David (org.). The Cambridge companion to John Cage. Cambridge: Cambridge University Press, 2002.

Submetido em 30 de setembro de 2020

Aceito em 21 de dezembro de 2020

Publicado em 14 de fevereiro de 2021 